\title{
Cecília Meireles por ela mesma e sobre outras mulheres: sua autobiografia e a representação do feminino no Brasil do início do século XX
}

\author{
Cecilia Meireles on herself and about other women: her autobiography and \\ women representation in Brazil in the $1900 \mathrm{~s}$ \\ Gisele Pereira de Oliveira \\ Universidade Estadual Paulista Júlio de Mesquita Filho - Assis - São Paulo - Brasil \\ $\diamond$

\begin{abstract}
Resumo: Cecília Meireles escreveu suas memórias em artigos publicados em Portugal com o título de Olhinhos de gato, entre 1938 e 1940. Disponível no formato de livro, esta obra é analisada neste artigo, primeiramente, pelo viés da teoria da autobiografia de Philippe Lejeune. Em um segundo momento, observa-se a representação do feminino no contexto sócio-histórico da infância da poetisa e, ademais, a gênese da autora. Dessa forma, considera-se, por um lado, o concreto, o tangível na obra, pelo social, e, por outro lado, o íntimo, o subjetivo, apreendendo o momento iniciático em que a Cecília se descobre como escritora.
\end{abstract}

Palavras-chave: Cecília Meireles; Philippe Lejeune; Autobiografia; Infância; Mulheres

\begin{abstract}
Cecília Meireles wrote her memories in a series of essays published in Portugal entitled Olhinhos de gato, between 1938 and 1940. Available as a book nowadays, this work is analyzed here, first, in terms of Philippe Lejeune's theory on autobiography. Secondly, not only is the representation of the feminine in the socio-historical context of the poet's childhood observed, but, moreover, we analyze the genesis of the author. This way, we take into consideration, on one hand, the concrete, the tangible aspect of the book, as its the social realm, and, on the other hand, the intimate, the subjective aspect as we look at the initiating moment in which Cecília recognizes herself as a writer.
\end{abstract}

Keywords: Cecília Meireles; Philippe Lejeune; Autobiography; Childhood; Women

\section{Introdução}

Cecília Meireles (1901-1964), poetisa, cronista, folclorista, educadora, conferencista, tradutora, publicou, entre 1938 e 1940, nas páginas da revista portuguesa Ocidente 1 , uma série de artigos intitulada "Olhinhos de gato", que se constitui - conforme indicação em nota do editor de sua publicação em livro - como "uma poética narrativa autobiográfica"2.

Nosso objetivo, aqui, é, por um lado, pensar a série na perspectiva do gênero autobiográfico, na tentativa de aferir-lhe o status como tal, e, por outro lado, considerála na perspectiva da extensa obra ceciliana, averiguando em que medida ela contribui para o projeto artístico

\footnotetext{
1 Olhinhos de gato, in: Ocidente, Lisboa, v. III, n. 7-8; v. IV, n. 9-11; v. V, n. 12; v. VI, n. 15-16; v. VI, n. 17-19; v. VIII, n. 20-23.

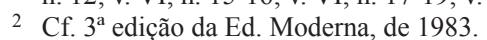

vitalício da autora em suas variadas abordagens (lírica, educacional, histórica, modernista).

\section{Cecília Meireles por ela mesma: sua autobiografia nos termos de Lejeune}

Cecília, em entrevista à revista Manchete, em 1964, classificou o conjunto de artigos "Olhinhos de gato" como "pequeno livro de memórias" cujas características seriam as de uma "narrativa sobre a infância" (apud LAMEGO, 2001, p. 50).

Essa narrativa sobre a menina Cecília se dá em terceira pessoa: uma narradora (pois a identificamos com a autora) que se apresenta onisciente (uma vez que transmite ao leitor os pensamentos, os questionamentos, as imaginações da menina), revelando-se como um duplo da criança protagonista, que, porém, mantém sua identidade adulta, por meio de um vocabulário e estruturas 
linguísticas complexas para uma criança, por exemplo. Dessa forma, nos parece ser a Cecília adulta que relembra sua infância, como a narradora de sua autobiografia.

Na perspectiva de Philippe Lejeune, uma autobiografia se define como um "relato de vida" centralizado na história da personalidade; mais detidamente, o gênero se caracteriza pela fala de si diretamente (cf. PACE, 2012, p. 46): "chamamos autobiografia a narrativa introspectiva em prosa que alguém faz de sua própria existência, quando ele [ou ela] enfatiza sua vida individual, em particular a história de sua personalidade" (Lejeune apud SOBRINHO, 2010, p. 104). Mais especificamente, de acordo com Lejeune, para que seja uma autobiografia, deve haver o "pacto autobiográfico" que ocorre uma vez que a personagem, o(a) narrador(a) e o(a) autor(a) coincidam:

A autobiografia (narrativa que conta a vida do autor) pressupõe que haja identidade de nome entre o autor (cujo nome está estampado na capa), o narrador e a pessoa de quem se fala. Esse é um critério muito simples, que define, além da autobiografia íntima (diário, auto-retrato, auto-ensaio). [...] $\mathrm{O}$ autor, representado na margem do texto por seu nome, é então referente ao qual remete, por força do pacto autobiográfico, o sujeito da enunciação (Lejeune apud VANDERLEI, 2012, p. 65-66).

Cecília satisfaz a necessidade de identificação entre a autora e a protagonista ao adotar um epíteto de "Olhinhos de gato", aparentemente adotados pelas outras personagens na narrativa para se referirem a ela. Mais do que isso, adota epítetos para as pessoas que fizeram parte de sua vida e são reconhecidas em sua história, como a avó Jacinta, que a criou na ausência dos pais falecidos, referida na narrativa como "Boquinha de doce", e sua ama Pedrina, cantada também em sua poesia, aqui, chamada de "Dentinho de arroz".

De fato, se considerarmos que por meio de uma autobiografia busca-se "um quadro minimamente inteligível e coerente" (BAKHTIN, 2006, p. 139), "para representar-se a si mesmo, é necessário reunir os valores biográficos de que tomamos conhecimento pela boca de outras pessoas, familiares, pessoas próximas" (SOBRINHO, 2010, p. 105). Portanto, a presença desses entes queridos na narrativa autobiográfica ceciliana faz parte da tentativa de se alcançar uma consistência e uma coerência ao juntar os fragmentos do "eu" na sua gênese, ou seja, na sua infância. Para Lejeune, apesar da dificuldade que as memórias fragmentadas da infância oferecem para o autobiógrafo, por serem as mais marcantes, são privilegiadas e, como recordações, como emoções, se expressam por meio do lirismo:
As lembranças da infância são descontínuas e incertas, mas frequentemente intensas [...] Mergulha-se diretamente no fundo de si, numa fonte de vida. É por isto que o regime banal da lembrança da infância é o lirismo. [...]

A narrativa da infância se apresenta, então, como uma busca iniciática,, da qual se mostram as dificuldades. A memória é fragmentada, as lembranças flutuam [...] É o estremecer da memória [...] (Lejeune apud SOBRINHO, 2010, p. 106).

Em Olhinhos de gato, em conformidade com as premissas de Lejeune, a linguagem se aproxima à linguagem poética: há a predominância da concisão, de elipses, reticências, imagens, metáforas - "cigarras de bronze e cristal sonoramente aderindo ao ganho rugoso"; "libélulas vestidas de vidro"; "e o fiozinho da água perdendo-se abandonado pela terra adiante, numa interminável lágrima"; "e o vento [...] aquele vento caricioso, subindo outra vez pela árvore acima [...] e fugindo pelo céu, perseguindo pássaros e empurrando nuvens" (MEIRELES, 1983, p. 5).

Por outro lado, há de se considerar que conforme Lejeune a autobiografia costuma ser analisada como parte do projeto intelectual de um escritor (Cf. PACE, 2012, p. 53) e, apesar de não poder, para ele, ser apenas estudada nessa perspectiva, mas sim como um gênero da literatura, aqui, este aspecto nos parece interessante. Cecília Meireles foi renomada poetisa e vendo sua autobiografia, como parte de seu projeto vitalício de produção, não se poderia deixar de pensá-la pelo viés do lirismo. Assim, nota-se em Olhinhos de gato, não a tentativa de reconstruir um quadro contínuo e coeso da infância ${ }^{3}$, ou "uma reconstrução de uma narrativa temporalmente linear, mas sim de momentos consideráveis para o delineamento de uma história de vida" (semelhantemente à obra de Laferrière - SOBRINHO, 2010, p. 111-112), mas, ao invés de um elencar de fatos, prefere-se "fazer surgir a emoção de uma situação" (idem, p. 112). Uma vez que a memória, ou a recordação, é a matéria da poesia, da lírica, Olhinhos de gato se constitui como uma autobiografia poética; parte do conjunto da obra ceciliana como um todo:

Impossível determinar a lógica do enredo do livro. Tal como ocorre no intrincado processo da rememoração, entrecruzam-se lembranças e esquecimentos, misturam-se temporalidades diversas, sobrepõem-se o real e o imaginário, interpenetram-se espaços, articulam-se corporeidade e espiritualidade, confundemse a mais pessoal das experiências com aquelas ouvidas de outrem, fundem-se fantasmagorias e concretude. Mas sempre num jogo de luzes e sombras projetadas sobre fragmentos do vivido (NEVES, 2001, p. 30).

\footnotetext{
3 Não há uma cronologia linear, dados precisos de seu nascimento, círculo familiar, datas, locais, etc.
} 
Parece-nos, assim, que conforme as asserções de Lejeune sobre a variabilidade da autobiografia como gênero, ou seja, "a complexidade da manifestação autobiográfica [que] envolve um sistema mais dinâmico de que o linear e do que as relações de igualdade e diferença" (PACE, 2012, p. 71), a obra autobiográfica de Cecília apresenta suas próprias características, apesar de poder ser considerada como exemplar do gênero nos termos do próprio Lejeune.

Dessa forma, Olhinhos de gato parece abarcar, como apontado por Neves, contraposições, opostos, extremos: ao mesmo tempo em que narra eventos prosaicos do cotidiano infantil, há momentos em que se intui outras instâncias, outros planos, talvez sublimes, talvez sobrenaturais, de forma que a narrativa parece se balizar no limiar entre o concreto e o sutil, o tangível e o transcendente.

Para exemplificar isso, trataremos de dois aspectos da obra: a representação das mulheres, por um lado, e o "rito de passagem", o momento iniciático da Cecília como escritora.

\section{A menina Cecília sobre outras mulheres: a representação do feminino em Olhinhos de gato}

Há um panorama da representação do feminino na infância ceciliana, que permite apreender aspectos sócio-históricos do início do século $\mathrm{XX}$ em relação às mulheres no Brasil sob os olhos da poetisa, afinal, "o externo (no caso, o social) importa, não como causa, nem como significado, mas como elemento que desempenha um certo papel na constituição de estrutura, tornando-se, portanto, interno" (CANDIDO, 2006, p. 14). Pode-se, assim, perscrutar como a mulher do início do século XX vive, e ao mesmo tempo como a Cecília se vê nesse período formador da "menina sozinha", em que surgiram seus primeiros livros como "o desenrolar natural de uma vida encantada com todas as coisas, e mergulhada em solidão e silêncio tanto quanto possível".

O feminino na obra ceciliana, "ao contrário do que afirma a crítica mais tradicional acerca da autora", como afirma Ana Maria Domingues, é tão reincidente, claro e pungente como diversos outros motivos no universo múltiplo de Cecília, diferentemente do que é preconcebido pela:

[...] leitura que, grosso modo, se tem feito da obra de Cecília Meireles [que] está já condicionada a encontrar, em seus textos, um modelo de feminino que se considera inerente à obra da poetisa, ou seja, etéreo, espiritual, alienado, assexuado, incorpóreo (DE OLIVEIRA, 2010)
Ao levar este equívoco aparentemente generalizado em consideração e "tentar ler a obra de Cecília com o desconforto e os olhos de quem procura as evidências contrárias a crenças tão firmemente estabelecidas pela crítica" (idem), nos deparamos com um universo marcadamente feminino em Olhinhos de gato, nesses "retalhos de uma memória que é de Cecília, mas que também pertence a outros que, como ela, foram crianças no Rio de Janeiro do início do século XX" (NEVES, 2001, p. 33).

Primeiramente, as personagens são majoritariamente femininas: a avó, a ama, a cozinheira, a tia, as vizinhas, as pedintes, as contadoras de estórias, a cigana, etc. (com raras exceções, como o cabeleireiro, o jardineiro, alguns vendedores de rua e o pedinte cego).

Em suas memórias infantis, Cecília evoca estas figuras femininas que estavam mais próximas a ela; pessoas com as quais ela mais convivia e decidiram sua formação, suas lembranças, sua história.

Ter notícias dessas mulheres significa saber da situação sócio-cultural delas neste contexto, pois:

Se levarmos em conta a situação da mulher numa sociedade, numa época determinada, [...] é claro que sua ficção e poesia vão-nos transmitir essa posição específica. Não que a obra literária seja reflexo da sociedade: ela é algo paralelo, não há uma relação de causa e efeito, mas é influenciada por uma situação econômico-social específica (JOZEF, 1989, p. 46).

Para Josef, a mulher parte da idealização de uma voz própria para melhor se expressar e expressar a posição das mulheres numa determinada sociedade, numa determinada época. Entretanto, da mesma forma que a sociedade delimita diferente papéis às mulheres, elas, em sua singularidade individual, apresentam vozes únicas, pessoais, semelhantemente à asseveração da Cremilda Medina de que, havendo um pluralidade de oportunidades quantitativamente plurais, há, consequentemente, o surgimento de singularidades artísticas, as quais são assexuadas; ou seja, a qualidade artística humana independe de gênero, podendo surgir desde que haja o estímulo, a ocasião, etc. necessárias para seu fomento (cf. MEDINA, 1989, p. 35).

Dessa forma, Cecília Meireles apresenta sua voz em Olhinhos de gato como uma menina e celebra a posição da mulher embalada em histórias e cantigas. Essa é sua voz, sua escolha de melodia para, nos parece, mais celebrar o feminino na sociedade do que criticar.

A partir das mulheres elencadas no cenário lírico infantil de Cecília, nota-se a delimitação do espaço de ação das mulheres do início do século XX ao doméstico, em atividades e convívio, mesmo considerando que 
trabalhassem, como sua babá e a cozinheira (agregadas assalariadas), conforme esses excertos:

Parece-se com a Edwiges, que engoma roupa de noite, num porão vazio, com um candeeiro de querosene. Parece-se com a Paulina, que amassa pastéis, em dias de festa, e com a Luísa, que é quem sabe mais histórias de lobisomem e almas de outro mundo (MEIRELES, 1993, p. 23).

Maria Maruca escorre o café e ferve o leite no fogareiro de carvão. Há um abano de palha, mas ela gosta é de soprar com a boca; incha as bochechas lustrosas e espalha a cinza. Abre a torneira em cima da louça, arruma as colheres nos pires (idem, p. 25).

Além de apresentarem o âmbito sócio-histórico no qual a menina Cecília cresce, essas mulheres têm a voz das estórias (folclóricas) e das cantigas (populares) que serviram de trilha sonora da infância encantada da poeta, e embasaram muito de sua produção, como pano de fundo a partir do qual seus próprios livros surgem:

Minha infância de menina sozinha deu-me duas coisas que parecem negativas, e foram sempre positivas pra mim: silêncio e solidão. Essa foi sempre a área da minha vida. Área mágica, onde os caleidoscópios inventaram fabulosos mundos geométricos, onde os relógios revelaram o segredo do seu mecanismo, e as bonecas o jogo do seu olhar. Foi ainda nessa área que apareceram um dia os meus próprios livros, que não são mais do que o desenrolar natural de uma vida encantada com todas as coisas, e mergulhada em solidão e silêncio tanto quanto possível (MEIRELES, 1994, p. 81-82).

Dentre as tantas contadoras de história, como "as negrinhas", que vêm almoçar e contar "histórias que parecem mentira", Cecília destacará a avó e a babá:

\begin{abstract}
Mas, se antes de saber ler já gostava de brincar com livros, antes de brincar com livros gostava de ouvir histórias. Minha pajem, uma escura e obscura Pedrina, que sobrevivera (embora não por muitos anos) à onda de sucessivas mortes que arrebatou toda a minha família, foi a companheira mágica da minha infância. Ela sabia muito do folclore do Brasil, e não só contava histórias, mas dramatizava-as, cantava, dançava, e sabia adivinhações, cantigas, fábulas etc. Por outro lado, minha avó, com quem fiquei, depois de perder minha mãe, sabia muitas coisas do folclore açoriano, e era muito mística, como todos de São Miguel (idem, p. 83).
\end{abstract}

Tantas são as referências a essas inúmeras histórias que lhe contavam "para ela comer com mais vontade", ou "depois do jantar, distraem-na para que não ador- meça" com "personagens extraordinários" (MEIRELES, 1983, p. 29).

Por um lado, há a avó, que, por exemplo, "falava-lhe da menina que tinha uma estrela de prata na testa" e, afora sua dedicação e amparo material à menina, passa a exercer influência marcante sobre a formação moral, conforme a escritora declara mais tarde: "A dignidade, a elevação espiritual da minha avó influíram muito na minha maneira de sentir os seres e a vida" (BLOCH, 1964, p. 34). E influi, igualmente, na sua formação intelectual, cultivando desde cedo seu interesse pela pátria portuguesa, mantendo viva a fala camoniana e a cultura local, bem como despertando seu interesse pela Índia e o Oriente, tudo corroborando para sua visão de mundo universal. Podemos citar alguns desses fatores, pela própria autora:

Quanto a Portugal basta dizer que a minha avó falava como Camões. Foi ela quem me chamou a atenção para a Índia, o Oriente: "Cata, cata que é viagem da Índia”, dizia ela, em linguagem náutica, creio, quando tinha pressa de algo. Chá-da-Índia, narrativas, passado, tudo me levava, ao mesmo tempo, à Índia e a Portugal (idem).

Por outro lado, Pedrina e sua aveludada voz que contava histórias, pois "conhece todos os bichos e as suas histórias" (MEIRELES, 1983, p. 30), "sabia muito bem como um cavalo vira um príncipe, e sai um palácio do fundo do mar" (idem, p. 38), ou que "conhece (pessoalmente) o Rei, a Rainha, a Fada, a Bruxa, o Gigante e o Anão [...] sabe do Saci-Pererê, do Lobisomem e da Mula-sem-cabeça" (idem, p. 44).

Sem dúvida uma das passagens mais doces dessas memórias é a da descrição da querida Pedrina ${ }^{4}$, com as impressões que Cecília tinha de sua presença, e que aproveito o ensejo para reproduzi-la aqui:

Dentinho de Arroz, Dentinho de Arroz. Gente mesmo? Ou boneca de pano? Tão macia... Tão silenciosa... Seus olhos negros - olhos ou miçangas? - mornos, levemente vesgos, destilando uma luz oleosa. Névoa tênue de buço, pelo sorriso. Névoa menos tênue de mágoa, no olhar.

Diante do pequeno espelho, enganchado num prego, seu cabelo se alarga numa densa fronte, eriçada e negra. Suas mãos finas, da cor de jacarandá, vão submetendo, em calmos movimentos de trança, a espessa massa que o óleo de coco ilumina de frisos metálicos.

\footnotetext{
4 Pela própria Cecília sabemos que aprendeu de Pedrina muito do folclore do Brasil, o que, se não quase por completo, embasou muito do seu trabalho sobre o tema, que incluiu uma série de desenhos sobre gesto e ritmo (1926-1934), a exposição destes no Brasil, em 1933, e em Portugal concomitantemente a três conferências em Lisboa, em 1934, a publicação do livro Batuque, Samba e Macumba (hoje, disponível em edição da Martins Fontes, de 2003), a participação da Comissão Nacional de Folclore, a partir de 1948, e da organização do I Congresso Nacional de Folclore, em 1951.
} 
E quando o penteado termina, então aparecem as pequenas orelhas, muito redondas, transpassadas por uma sutil argolinha de ouro. Seu sorriso forma duas covinhas na face. E sobre o lábio estremece um sinalzinho preto.

Subir a ladeira sentada no seu ombro é uma aventura como um passeio por cima do vento, sentindo as pedras diminuírem, e as estrelas e as nuvens aproximarem-se. $[\ldots]$

Brincar ao seu lado é sair invisível, e viajar por países azuis e dourados, onde os peixes conversam com as princesas, os pássaros puxam carros festivos, e as palavras, ditas três vezes, formam e desfazem as pessoas e as coisas mais impossíveis. [...]

É bom dormir sobre o seu peito, diferente dos outros. Uma curva diferente. E um outro cheiro. Encostada nela, a menina pensa viajar para longe, para a roça, pelo mato, onde moram animais engraçados, de nomes esquisitos [...] Seus dedos têm uma doçura boa. Quase não pousam: e a gente fica sentindo-os para sempre! (idem, p. 43-46).

Este relato da menina órfã de seu relacionamento com sua ama nos apresenta um dos episódios líricos da obra ao mesmo tempo em que sugere aspectos da memória, resgatados para a autobiografia, dando coerência e sentido à história de Cecília, provavelmente justificando sua missão de vida, sua produção escrita e a militância na educação: a importância do ouvir estórias para a formação da criança; o encantamento que sentiu ao ouvi-las e que perdurou nela inspirando-a em sua arte, formando sua visão de mundo, cristalizando-se em emoções acionáveis por intensas, íntimas, formadoras de quem ela veio a ser.

Outro aspecto interessante a ser notado aqui, em termos da representação do feminino, é a consciência da menina Cecília de ser do gênero feminino em oposição ao masculino, como demonstra a passagem em que se esconde para não conhecer o "priminho":

Quando saiu de seu esconderijo, Boquinha de Doce também tinha chegado: 'Mas onde isto se foi meter! E todos procurando! E a tia Tota... e o priminho...'

Mas seus cabelos estavam despenteados, e o vestido todo torcido no corpo. 'Venha conhecer o priminho!' Não, o priminho ela não queria conhecer de modo algum. Os meninos, caçadores de borboletas e passarinhos, amarradores de caudas de libélula e rabos de gato, quebradores de vidraça e apedrejadores de frutas, constituem uma casta de sua profunda antipatia. Não queria saber do primo. Eram eles, os meninos, que, depois de crescidos, se transformavam em ladrões. Positivamente, não queria saber dessa gente. [...]

Mas é tão teimosa, tão teimosinha... Muito esquisita. ESQUISITA. Embirra com as coisas e com as pessoas, não se sabe por quê. [...] Às vezes são outras coisas: pois não havia de cismar com um vestido que a madrinha lhe deu: 'Porque não boto, porque não boto: porque este vestido é de homem... eu não sou homem, eu não boto o vestido'. Levou nessa lengalenga, e não botou o vestido! Um vestido tão bom! De brim com uns risquinhos. Tudo porque não queria ser homem [...] (idem, p. 103).

Não só há a identificação como menina, contrária ao menino, baseada na identificação das (e aversão às) atividades tipicamente masculinas, como as brincadeiras maldosas e o estereótipo de homem-bandido, mas também o desejo de não ser homem, de não se parecer com homem com a recusa de usar um vestido "porque este vestido é de homem" (E nos perguntamos o que seria um "vestido de homem" para a menina Cecília).

Este é um breve panorama do universo feminino da infância de Cecília: cercada por mulheres em seus afazeres do âmbito doméstico, mas envoltas em cantigas e histórias que herdaram da tradição oral e as transmitiram à menina que, posteriormente, registraria e perpetuaria parte desse legado em imagem (desenhos), escrita (prosa e poesia), e verbalmente em aulas e conferências no Brasil e no exterior. Mulheres que serviram de memória viva para a poeta, memória da sua família, da cultura (afro-)brasileira, da sabedoria popular.

\section{A menina Cecília por ela mesma em seu rito iniciático como escritora: os olhos que apreenderam o mundo e o além-mundo}

Olhamos para o primeiro texto como autobiográfico e consideramos suas implicações. Por um lado, este se dá entre o pessoal e o social, como tentamos demonstrar acima, e como nos diz Marcela E. dos Santos:

O tema principal da autobiografia são as experiências concretas e o registro da realidade pessoal. Não podemos deixar de mencionar que a escrita do eu está associada ao contexto histórico-social em que foi produzida, sendo capaz de trazer muitas vezes, informações preciosas sobre o período do qual foi fruto, e assim, contribuir para mudanças políticas e sociais (SANTOS, 2010, p. 12).

Por outro lado, há a profundidade da exposição pessoal, com tom confessional, mesmo que a narrativa se dê a partir da tensão entre a memória e a re-elaboração dessa, por meio dos manejos da ficção.

Quanto ao tom confessional, diz-se que:

Foi ele [Philippe Lejeune] quem instituiu o conceito de pacto autobiográfico, uma espécie de acordo que se firma entre quem escreve e quem lê. Em tal contrato, o autobiógrafo se compromete explicitamente a uma apresentação sincera de sua vida enquanto o leitor, por sua vez, deve buscar revelações que possam ser comprovadas extratextualmente (ibidem, p. 13). 
Desta forma, entrar no universo autobiográfico da Cecília nos parece uma trajetória real em direção à pessoa Cecília, ao seu íntimo, uma vez que é uma "experiência textual de alguém que quer contar sua vida para dizer quem é", como afirma Bella Joseff (apud SANTOS, 2010, p. 14). Em outras palavras:

[...] o destinatário [o leitor] pode questionar a veracidade dos fatos, mas não da identidade do autor. [...] A escrita confessional tenta, por meio de relatos íntimos, abarcar o indizível, resgatar no instante da escrita um tempo perdido que se desfez na vulnerabilidade do chronos, mas que permanece na memória do ser (idem).

Se a escrita autobiográfica da Cecília se dá no sentido de dizer quem é (para si mesma e para o leitor), nota-se que a maneira de fazê-lo corresponderá a seu estilo indagativo, em busca de porquês: "Por que tudo é tão triste? Por que é mais triste, tudo, de repente?" (MEIRELES, 1983, p. 32); "Por que seria que resolveram cortar-lhe os cachos?" (idem, p. 127); "Como poderia explicar o que estava sendo, fora da sua vida?" (idem, p. 134), em tom rememorativo, como é notório em sua obra poética e outras produções em prosa. Para Neves é:

Refletidos no espelho das lembranças, os episódios vividos e as sensações experimentadas se multiplicam, como num caleidoscópio, e ganham novos significados, entramados com a imaginação da escritora adulta, que tantas vezes utilizou em sua poesia a metáfora do espelho (2001, p. 31).

Neves também defenderá que a obra, destinada a conhecer-se/dar a conhecer, se dá entre dois pontos demarcados na vida da autora: a compreensão da morte (dos parentes) e o corte dos cachos alourados (como rito de passagem). Concordamos com a premissa parcialmente, pois há sim um rito de passagem, mas o que faltou articular é que, para nós, este rito de passagem simboliza o nascimento da menina escritora, da poetisa.

Primeiramente, a menina passa pelo reconhecimento da mudança física:

E viu-se a si mesma, de novo, no espelho, - mas uma outra, diferente da anterior, perdido aquele ar mais infantil dos cabelos esvoaçantes, onde a luz armava surpresas de claridade - mais séria agora, com os cabelos concentrados num tom mais escuro, parados, quietos, unidos, tristes (MEIRELES, 1983, p. 129).

$\mathrm{O}$ rito de passagem demarca a mudança da infantil menina para alguém com aspecto "mais sério", que "era e não era ela" (idem, p. 131), o que é ratificado pela reação da avó: "Está ficando mocinha... Ainda parece mentira!..." (idem). E, então, recebe da avó a dádiva que concretizará o rito de passagem: "Boquinha de Doce deu-lhe uma cadeirinha de vime. Ela sentou-se para ver a rua $-e$ viu $o$ mundo" (idem - grifo nosso).

Este mundo que sempre esteve ali, à espreita, intuído, suspeito, latente, agora, chegada a hora, pronta a observadora, a iniciada, se abre em toda sua dimensão, como matéria-prima da produção literária, da poesia que se proliferará na vida da menina Cecília: "E a criança compreendia o mistério do touro de cabeça humana, do touro de barbas que existia dentro de um livro..." (idem, p. 132).

Sua introdução aos mistérios, à inspiração, se dá, então, no texto, em uma sequência que mimetiza um transe sutil disposto aos olhos do leitor, primeiramente, com o chamado para o jogo do bicho, em uma discussão entre "as mulatinhas" sobre os bichos enumerados, invocados e "o sonho é munto bão. O sonho ensina tudo" (idem). Estamos em transe, em estado onírico, envoltos pelos bichos, "a barbuleta", "o elefante", "a cobra", "o pavão". Em seguida, entram "as mulheres morenas", as ciganas, que passam a ler a sorte nas palmas das mãos, fazem revelações, profecias:

OLHINHOS DE GATO ficava olhando para a palma da sua mão. Cada risquinho daqueles queria dizer então uma coisa... E suas mãos eram tão riscadas... [...] 'Essa menina vai ter uma vida muito atrapalhada... Só dificuldades, só dificuldades...' Mas Boquinha de Doce, que lhe afagava o cabelo, murmurou: 'Talvez não... Oxalá que não... E há de ser o que Deus quiser...' (idem, p. 132-133).

Finalmente, para o clímax do transe iniciático, entra em cena "o cego, de rosto erguido, com uma bengala, um menino e um cão"; o emblemático cego, o profeta, o barqueiro, o bardo? O cego que "não falou" e "não sabia nem o passado, nem o futuro, nem o presente" (idem, p. 133). Mas o rito precisava ser concluído e, assim:

Ela levantava e arrastava a cadeira, as ciganas, o cego, o perna-de-pau. Andava com eles por dentro da casa. Conversava com eles. E fazia-os conversar uns com os outros. [...]

Dessa cadeira, e debruçada para o mundo, foi que ela realizou seu imenso descobrimento (idem - grifo nosso).

Qual descobrimento?

Passou a ser cega e viver no mundo dos cegos - com a noite por todos os lados e apenas a própria memória sustendo a noção de sua presença: como uma pessoa perdida de noite numa casa escura e fechada. Como um enterrado vivo com as mãos pelas raízes, por baixo do chão... Assim esteve a menina ceguinha [...]

Quando recuperou a vista, OLHINHOS DE GATO compreendeu que voltava de uma profunda viagem, e realizara um imenso descobrimento. [...] 
Sem sair do lugar andou por estranhos lugares, e sem que ninguém reparasse passou para dentro de todas as vidas. $[\ldots]$

E tudo era ser e deixar de ser. Como quem despe um vestido, como quem solta um brinquedo e apanha outro: assim. Assim facilmente. E não apenas pessoas: mas também os animais. [...]

Então, foi vegetal também. [...]

E fechou-se dentro desse chão. E deitou-se inerte entre os mortos. 'Ossinhos... Os ossinhos...' Fez-se ossos, apenas. [...] E ela estava ali sentada, sorrindo, e enterrada, e acabada, misturada com as sementes, as formigas, as conchas. [...]

E como todas essas vidas ainda eram consistentes e limitadas, afrouxou suas moléculas, dispensou qualquer contorno, espraiou-se na fumaça das nuvens, dissipou-se indeterminadamente pelo céu, foi tudo e nada ao mesmo tempo, sem lado de cima, sem lado de baixo, entregue ao campo que há por detrás do mundo, e por onde se rola sem nome, sem figura e sem fim (idem, p. 133-135).

E nasceu a escritora, a poetisa... desse nirvana: a possibilidade de ser/estar com todas as coisas, todos os seres, sentir-lhe a vida pulsante e assumir suas personas, saindo dessas excursões munida de histórias a serem contadas; ser vidente, vivendo no limiar entre os mundos, entre o tangível e o transcendente.

Esse é o rapto místico de Olhinhos de gato, que vê e, assim, vive, experimenta, e, por isso, pode falar, narrar, registrar, para, quem sabe: "Acordar a criatura humana dessa espécie de sonambulismo em que tantos se deixam arrastar. Mostrar-lhes a vida em profundidade. Sem pretensão filosófica ou de salvação - mas por uma contemplação poética afetuosa e participante" (MEIRELES, 1994, p. 80).

\section{Reflexões finais}

Parece-nos relevante ressaltar a convergência que existe entre a obra em prosa de Cecília e sua lírica. Muitos dos episódios, dos objetos, das personagens de sua autobiografia (e de sua produção em crônicas) está presente como motivos em diversos poemas. Há, dessa forma, a coerência, a junção dos fragmentos do "eu", a construção de uma história individual (mesmo que não acabada, pois se trata de objetivo provavelmente inalcançável) de Cecília no conjunto de sua obra, conforme aponta os preceitos da autobiografia de Lejeune que, neste caso, transbordam a obra autobiográfica, Olhinhos de gato, e permeiam aparentemente quase toda a produção ceciliana.

A propósito de síntese e exemplo, reproduzimos aqui um dos poemas intitulados "Papéis", que se configura como um poema autobiográfico de Cecília:

\section{Papéis}

Naquele tempo, o que eu mais desejava era uma árvore. A mangueira.

E minha avó plantou a mangueira no jardim.

Cresceu devagar, com dificuldade.

Sofria de uma doença que a envolvia,

de vez em quando parecia afogada numa teia de aranha, como se fosse morrer.

Afinal, atingiu a altura da janela do quarto.

Nesse ano, minha avó morreu.

E eu, sentada à beira da cama,

via-a aparecer na janela.

\section{II}

Muitas histórias melancólicas envolvem as crianças. Às vezes, eu estava brincando com os meus bonecos, mas estava pensando no bastidor da mamãe, com um bordado interrompido, e em coisas antigas, que estavam por ali, e que tinham vindo de casas acabadas, de pessoas acabadas, de um mundo acabado.

Era a minha família.

III

Meu avô, que não conheci, morreu debaixo do cajueiro, de repente.

Ao lado do manacá plantado por suas mãos.

Logo que um manacá floresce,

vejo esse avô que não conheci.

Um avô jovem, belo de olhos verdes,

e as lágrimas de minha avó abraçada ao seu peito.

Seu peito, ela recordava,

era branco, firme, polido - um marfim.

IV

Minha infância foi sobre um velho tapete oriental.

Nele aprendi a beleza das cores.

Nele sonhei com as raízes do azul e do encarnado.

E sempre me pareceu que o desenho era uma escrita: que o tapete falava coisas, eu é que ainda o não podia entender.

V

Mas por que sempre lembrar essas coisas longínquas? A verdade, porém, é que há uns dias inesquecíveis, uns fatos inesquecíveis, dentro de nós.

Tudo o mais, que vivemos, gira em redor deles.

Toda uma vida se reduz, afinal, a umas poucas emoções, por muitos anos que vivamos,

apesar de viagens, experiências, sonhos, saber...

Vivemos tudo - o humano e universal -

nuns pequenos instantes, obscuros e essenciais. 
Todos os dias assim, de chuvinha fina, penso em velhas cenas da infância:

a tarde em que comia um pedaço de maça

e conheci o arco-íris; o livro em que estudava francês, com uma gravura de crianças felizes, que riam para o ar:

"Brinquedos para os dias de chuva..."

Tudo isso vem à minha memória, como visitantes inesperados.

Interrompo o que estou fazendo, tenho uma pena imensa de mim.

Depois, penso em velhos poemas chineses, curtos e leves.

Sou como quem mira uma antiga coleção de cartões-postais.

Setembro, 1955 (in: Dispersos)

Este poema além de retomar diversos episódios do livro Olhinhos de gato, aborda a perspectiva da narrativa autobiográfica, estimulada pela indagação: "Mas por que sempre lembrar essas coisas longínquas?" E o sujeito lírico, Cecília, responde com a impressão de que há eventos que nos escolhem, que nos definem, e são esses que rememoramos para nos lembrar de quem somos, quem fomos, mesmo que com "pena imensa" de nós mesmos.

Por outro lado, discorremos nesse trabalho sobre aspectos panorâmicos do feminino na obra confessional da Cecília, pois "as lembranças apoiam-se em fatos e acontecimentos históricos ampliando os aspectos da história brasileira, e trazem detalhes dos cenários pouco iluminados pelos refletores históricos" (SANTOS, 2010, p. 13) - como é o caso das mulheres e sua história.

\section{Referências}

BAKHTIN, Mikhail. Estética da criação verbal. São Paulo: Martins Fontes, 2006.

BLOCH, Pedro. Pedro Bloch entrevista Cecília Meireles. Revista Manchete, n. 633, p. 34-37, maio 1964.

CANDIDO, Antonio. Literatura e sociedade. Rio de Janeiro: Ouro sobre azul, 2006.
JOSEF, Bella. A mulher e o processo criador. In: COELHO, Nelly et al. Feminino singular. São Paulo: Edições GRD, 1989. p. 43-59.

LAMEGO, Valéria. Crônicas de uma vida. Revista Cult, São Paulo, ano V, n. 51, p. 48-51, out. 2001.

MEDINA, Cremilda, de A. Os anos 60 e a revolução feminina. In: COELHO, Nelly et al. Feminino singular. São Paulo: Edições GRD, 1989. p. 34-41.

MEIRELES, Cecília. Olhinhos de gato. 3. ed. São Paulo: Moderna, 1983.

MEIRELES, Cecília. Poesia Completa. 4. ed. Rio de Janeiro: Nova Aguilar, 1994.

NEVES, Margarida de Souza. Paisagens secretas: memórias da infância. In: NEVES, Margarida de Souza et al. (Org.). Cecília Meireles: a poética da educação. Rio de Janeiro: Ed. PUC-Rio/ Loyola, 2001. p. 23-40.

OLIVEIRA, Ana Maria Domingues de. Figuras femininas na poesia de Cecília Meireles. Disponível em: $<$ http://www. uesc.br/seminariomulher/anais/PDF/ANA \%20MARIA $\% 20$ DOMINGUES\%20DE\%20OLIVEIRA.pdf>. Acesso em: 14 abr. 2013.

PACE, Ana Amelia Barros Coelho. Lendo e escrevendo sobre o pacto autobiográfico de Philippe Lejeune. 2012. Dissertação (Mestrado em Língua e Literatura Francesa) - Faculdade de Filosofia, Letras e Ciências Humanas, Universidade de São Paulo, São Paulo, 2012. Disponível em: <http://www.teses.usp. br/teses/disponiveis/8/8146/tde-06122012-143422/>. Acesso em: 14 abr. 2013.

SANTOS, Marcela Ernesto dos. Autobiografia feminina: a identidade e o preconceito nas memórias de Carolina Maria de Jesus e Maya Angelou. Revista Iluminart do IFSP, v. 7, n. 4, p. 12-20, abr. 2010. Disponível em: <http://www.cefetsp.br/ edu/sertaozinho/revista/volumes_anteriores/volumelnumero4/ ARTIGOS/2.pdf>. Acesso em: $1 \overline{4}$ abr. 2013.

SOBRINHO, Ataiena V. da L. Miguel. A narrativa autobiográfica da infância: arrebatados pelos sentidos em L'odeur Du café, de Dany Lafarrière. Revista Criação \& Crítica, São Paulo, n. 4, p. 103-118, abr. 2010.

VANDERLEI, Wanessa Rayzza L. de F. M. Nas tuas mãos: a fratura do pacto autobiográfico. In: Revista Desassossego, São Paulo, n. 8, p. 58-68, dez. 2012.

Recebido: 16 de abril de 2013

Aprovado: 19 de setembro de 2013

Contato: gisele_usp@yahoo.com.br 